\title{
Seismicity pattern of the Betic Cordillera (southern Spain) derived from the fractal properties of earthquakes and faults*
}

\author{
$\mathrm{J}$ Henares Romero ${ }^{1, \uparrow}$ C López Casado ${ }^{1} \mathrm{~J} \mathrm{Badal}^{2}$ and $\mathrm{J}$ A Peláez ${ }^{3}$ \\ ${ }^{1}$ Department of Theoretical Physics and Cosmos, University of Granada, Av. Severo Ochoa s $/ n$, \\ 18071 Granada, Spain \\ ${ }^{2}$ Physics of the Earth, Sciences B, University of Zaragoza, C/ Pedro Cerbuna 12, 50009 Zaragoza, Spain \\ ${ }^{3}$ Department of Physics, Higher Polytechnic School, University of Jaén, C/ Virgen de la Cabeza 2, \\ 23071 Jaén, Spain
}

\begin{abstract}
Several studies on earthquake occurrence and associated faulting have demonstrated that both phenomena have a scale-invariant behavior which can be analyzed by means of a set of non-integer dimensions $\left(D_{q}\right)$ describing their fractal properties and the calculation of multi-fractal spectra. It is the case that the behavior of these spectra is asymptotic at the ends of the variation interval of $q$, which is a real number that enters into the definition of the partition function of the dataset. The difference between the extreme values, called multi-fractal spectrum slope, is used to investigate the heterogeneity of the spatial distribution of earthquakes and fault systems. In this paper we focus on the Betic Cordillera, southeastern Spain, which is commonly considered the contact between the Eurasian and African plates and has an important seismic activity in the context of the Iberian Peninsula. Some of the most conspicuous Iberian earthquakes, such as the $1829 m_{\mathrm{b}} 6.3$ Torrevieja and the $1884 m_{\mathrm{b}} 6.1$ Alhama de Granada earthquakes occurred in this mountain range and both reached intensity X. The present work implies a new analysis based on the slope of multi-fractal spectra and referred to the historical seismicity of the region, specifically $b$-value (frequency distribution of earthquakes respect to magnitude), epicentral location, seismic energy and faulting. On this basis we propose a seismotectonic zonation that is contrasted with the stress state and the geodynamical evolution of the Betic Cordillera.
\end{abstract}

Key words: fractal dimensions; multi-fractal spectrum slope; seismotectonic; Betic Cordillera CLC number: P315.5 Document code: A

\section{Introduction}

Fractal objects can be defined as those for which the Hausdorff dimension (Mandelbrot, 1982) is lower than the topologic dimension of the space containing them (Vicsek, 1992). The fractal dimension $D$ is used to elaborate a representation of the whole fractal set. This dimension $D$ indicates how much space does a fractal set fills. In other words, the more objects has a fractal set, the greater is its fractal dimension. It is a way to estimate the size of the irregularities of a fractal set when zoomed down to finer scales. The fractal $D$ di-

\footnotetext{
* Received 16 April 2010; accepted in revised form 13 June 2010; published 10 August 2010.

* Corresponding author. e-mail: henares@gmail.com

(C) The Seismological Society of China and Springer-Verlag Berlin Heidelberg 2010
}

mension provides information about the geometric properties of the set being represented.

On the one hand, there are many ways to define the fractal dimension of a certain set, but different theoretical approaches lead to different values of $D$ and consequently to different properties. Therefore, when calculating $D$ value, it is necessary to establish the definition upon which the calculation is based. On the other hand, fractal sets can be homogeneous or heterogeneous, that is, uniform and symmetric or non-uniform and asymmetric, respectively. The mono-fractal sets are homogeneous in terms of scale properties and they need a single dimension to be described (Stanley et al, 1999). But if the description of the scale properties of the set requires more than a single exponent, then the set is called multi-fractal. There are a plenty of multi-fractal phenomena 
in the nature (Mandelbrot, 1989). Their characterization requires the use of more than one non-integer dimension which are known as multi-fractal spectrum.

The behavior of any physical system is determined, at least partially, by the spatial distribution of a certain scalar magnitude, such as the particle concentration, the voltage, the energy emitted by a cluster of earthquakes, etc. Spatially stationary distributions are called fractal or multi-fractal measures. They are related to the study on the distribution of a physical magnitude on a geometric surface. This surface containing the fractal measure can be an ordinary plane, the surface of a sphere, etc. Normally, a multi-fractal measure has an infinite number of singularities, so that the whole surface can be represented as a series of cross-linked fractal subsets whose fractal dimension $D$ depends on the singularity defining them, so we talk about generalized dimensions $D_{q}$. That division into subsets justifies precisely the use of the term "multi-fractal".

Several studies on the spatial variation of the fractal dimension of the $b$-value focus separately on earthquakes (Bhattacharya et al, 2002; Singh et al, 2008, 2009) and faults (Öncel et al, 2001). The present study addresses a more complete analysis since it takes into consideration both earthquakes and faults in the Betic Cordillera. In addition to $b$-values defining the magnitude-frequency relationship of earthquake occurrence in this region, the managed data refer to three different types of measures used to calculate in each case of the multi-fractal spectrum, namely, the location of the earthquakes, the energy released by the earthquakes and the location of the fault systems. All these measures are used in the study of the spatial variation of the multi-fractal spectrum slope. The results obtained, together with the spatial variation of the $b$-value, are used to give an overview of the Betic Cordillera based on the fractal character of their spatially distributed earthquakes and faults, and also to propose a seismotectonic zonation which is discussed in the light of the stress field and the regional geodynamics.

\section{Tectonic setting and faulting}

The study area is situated in the contact zone between the Eurasian and African plates, which stretches from west to east between Azores and Tunisia. These two plates are undergoing a gradually approach in NW-SE direction (Buforn et al, 1988a; Udias and Buforn, 1991; Henares et al, 2003) although the tectonic movements vary from WNW-ESE to NNW-SSE direc- tion depending on the zones (Henares et al, 2003).

The boundary between the Eurasian and African plates is difficult to be determined with accuracy. From the west of the Iberian Peninsula to the area of Gorringe the border is relatively clear, but from this point eastwards the large number of fracture lines on the terrain makes it rather difficult to establish its real position. The boundary spreads likely to Gibraltar, but following more than a single alignment (López Casado et al, 2001). The same uncertainty is observed to the east of Gibraltar, although the plate boundary runs towards the coast of $\mathrm{Al}-$ geria where it would probably be sharper. However, from the study of the epicenters of the earthquakes occurred in the Betic-Rif complex, it has been deduced that the plate boundary is a deeply fractured area. The large number of seismic sources needed to adjust the spatial distribution of the earthquakes to the main directions of the faults present in this area reveals its complexity (Sanz de Galdeano and López Casado, 1988; Molina, 1998; Peláez, 2000; Sanz de Galdeano et al, 2003).

The Betic Cordillera and the Rif Mountains (north of Morocco) are the westernmost edge of the Mediterranean Alpine orogen (Figure 1). The Betic Cordillera, with a width of $200 \mathrm{~km}$ approximately, stretches along $600 \mathrm{~km}$ to the south and southeast of Spain. The cordillera is divided into external and internal units and Neogene basins. To the south lies the Alboran Sea with continental crust subjected to thinning during the Lower and Middle Miocene (López Casado et al, 2001).

After the structuring period of the Betic units by slipping mantles, several groups of faults were originated within the Betic-Rif complex (Sanz de Galdeano and López Casado, 1988). The Betic Cordillera comprises three main groups of faults (Figure 2). The largest ones in $\mathrm{N} 60^{\circ}-90^{\circ}$ direction can be sorted into two subgroups in $\mathrm{N} 60^{\circ}-70^{\circ}$ and $\mathrm{E}-\mathrm{W}$ directions: the faults from Cadiz to Alicante and the faults of the corridor of the Alpujarra Mountains, and those of the coast of Malaga and Almeria in E-W direction. Other group of faults extends all along of the Betic Cordillera in NW-SE direction. The main fracture lines of the zone are in the region of Nerja and the basins of Granada and Tiscar. Another group runs generally in NE-SW direction and can also be divided into two subgroups of approximated directions $\mathrm{N} 10^{\circ}-20^{\circ}$ and $\mathrm{N} 40^{\circ}-50^{\circ}$. Among the faults belonging to this last group, the most remarkable are the faults of Lorca in the SE of the Iberian Peninsula, and those of Carboneras and Palomares spreading in SSW direction to the Alboran Sea and reaching the Alboran 


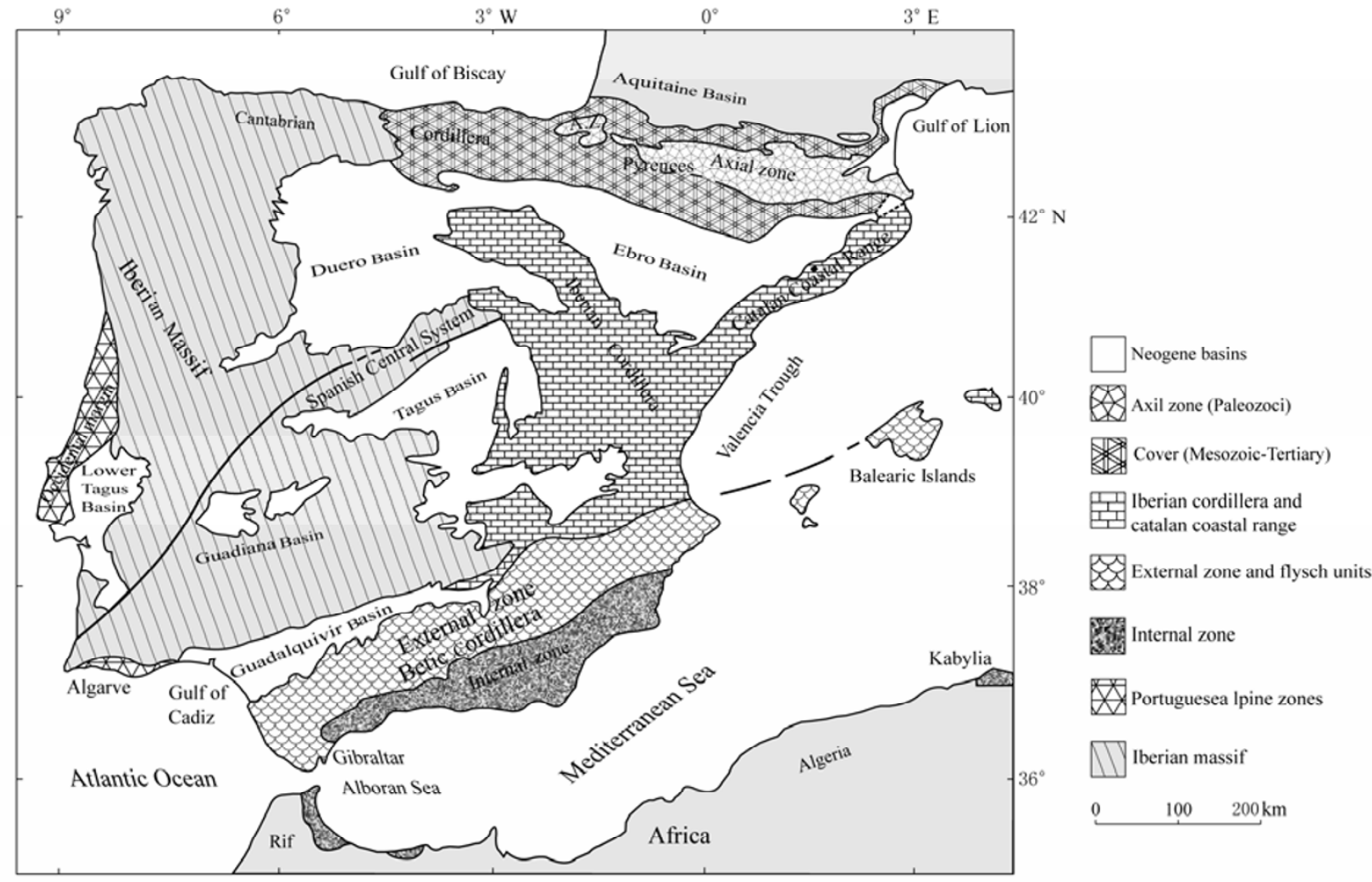

Figure 1 Schematic setting of the main tectonic units of the Iberian Peninsula according to their age and orogeny (in brackets) (after Sanz de Galdeano, 2000).

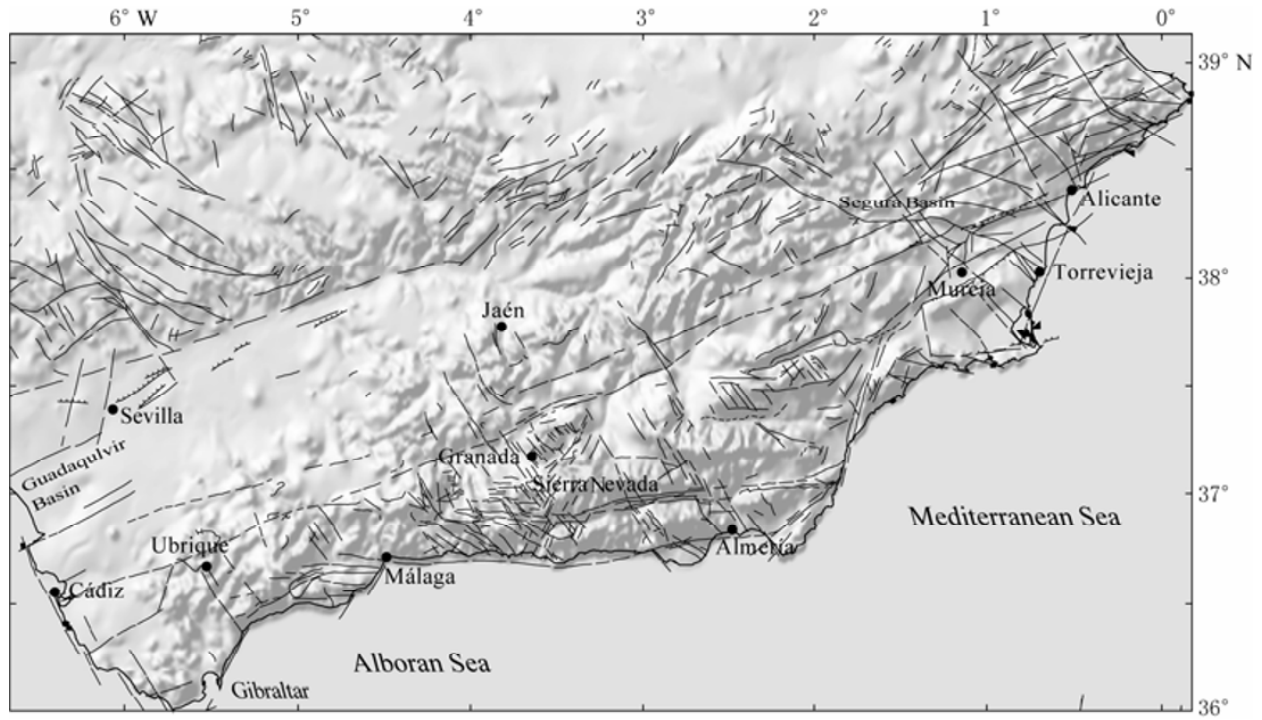

Figure 2 Faults identified in Southern Iberia (M.O.P.T., 1992) and further digitized.

Island and the Rif Mountains (Hernández et al, 1987).

\section{Present-day stress field}

The contact between the Iberian and African plates means a compression stress in NW-SE direction. Westwards, in the Atlantic Ocean, this direction changes to
WNW-ESE (Moreira 1985; Grimison and Chen, 1986; Buforn et al, 1988a; Udías and Buforn, 1991; GalindoZaldívar et al, 1993; Henares et al, 2003). In the zones of Algeria and Tunisia the direction of compression varies to NNW-SSE (Udías, 1982; Udías and Buforn, 1991; Medina and Cherkaoui 1991; Galindo-Zaldívar et al, 1993; 
Bezzeghoud and Buforn, 1999; Henares et al, 2003) thus matching up with other alignment.

As mentioned above, the contact between both plates around the Betic Cordillera and Alboran Sea is difficult to be determined exactly, and so happens with the stress state. In general, this area is subjected to a horizontal compression whose direction can vary from NW-SE to N-S (Buforn et al, 1988b; Coca and Buforn, 1994; Buforn et al, 1995; Mézcua and Rueda, 1997; Proyecto Sigma, 1998; Herráiz et al, 2000; Henares et al, 2003). Nevertheless, some local stresses in the region have been reported by several authors. For instance, Henares et al (2003) have found an extension in ENE-WSW direction in the Betic Cordillera and also other one in NNE-SSW direction in the Alboran Sea. In Alicante, Coca and Buforn (1994) early reported an extension in NNE-SSW direction; however, Alfaro et al (1999) claimed a compression stress in NNW-SSE direction and too Henares et al (2003) but in N-S direction, without discarding that this compression could be influenced by the NNE-SSW stress field between the Iberian Peninsula and France (Cortés and Maestro, 1998).

\section{Geodynamic evolution}

Several theories about the geodynamics of the Betic Cordillera have been formulated. An important fact to be stressed is that the continental crust is extremely thin in the Alboran Sea, with a thickness less than $15 \mathrm{~km}$ (Hatzfeld and Boloix, 1976). In addition, intermediate depth seismicity takes place in this region, forming a convex arc westwards, what has been taken as an evidence for subduction (Buforn et al, 1995; Morales et al, 1999; Gutscher et al, 2002); although it could be a consequence derived from the interaction of the Alboran lithosphere with the Eurasian and African plates with the result of folding, sinking and an incipient subduction (López Casado et al, 2001). In any case, this convex seismic alignment presents a complex dynamic pattern with pressure changes with depth, so that either horizontal or vertical compression could find accommodation (Henares et al, 2003). Recently, Jolivet et al (2009) have suggested that in the main regions of the Mediterranean Arc, and particularly in the Betic Cordillera, the lithosphere deforms with the same direction of stretching in the crust and mantle that would imply that the crustal deformation is mainly controlled from below by slab retreat.

\section{Regional seismicity}

Considering the earthquakes with greatest magnitude, it is possible to distinguish clearly up to four different seismic alignments in terms of superficial seismicity (López Casado et al, 2001). The first includes the longitudes $18^{\circ} \mathrm{W}$ to $10^{\circ} \mathrm{W}$ in direction WNW-ESE and marks exactly the boundary between the Iberian and African plates. In this transect the seismicity level is high. Between $10^{\circ} \mathrm{W}$ and $3^{\circ} \mathrm{W}$ the alignment changes its direction from E-W to ENE-WSW. Beyond $6^{\circ} \mathrm{W}$ there is a transition zone that can be translated into figures: the $b$-value is 0.74 before crossing this zone and 1.1 in the other side. The longitude $3^{\circ} \mathrm{W}$ marks the end of the third seismic alignment which extends to the southern coast of Spain passing through the eastern zones of the Alboran Sea and the Middle Atlas mountain range. The parameter $b$ takes the maximum value of 1.3 to the north and 0.9 to the south. The fourth alignment goes from latitude $1^{\circ} 30^{\prime} \mathrm{W}$ onwards, in direction $\mathrm{E}-\mathrm{W}$ to ENE-WSW after crossing a zone with lack of seismicity, and reaches the longitude $10^{\circ} \mathrm{E}$ to the north of Algeria and Tunisia. The easternmost zone has a $b$-value equal to 1.0 , while it is 0.8 in the middle and western transects. Some of the alignments observed at surface are also observed from intermediate depth seismicity.

The focal depth of the seismic events in the contact zone ranges between intermediate and deep $(30 \mathrm{~km}<h<$ $200 \mathrm{~km}$ ), especially in the region of the Gulf of Cadiz and western area of the Alboran Sea. It is known that south of Granada there is a focus of deep seismicity $(h>600 \mathrm{~km})$ possibly below the intermediate depth earthquakes to the west of the Alboran Sea (López Casado et al, 2001).

Between 1400 and 1909 there have been 16 earthquakes of intensity VII, 14 of intensity VIII, 2 of intensity IX and 2 of intensity X (Table 1) (López Casado et al, 2000; Mézcua et al, 2004). The 1748 Estubeny (Valencia) earthquake of intensity IX is out of the study area. The most destructive Iberian earthquakes have taken place in the Betic Cordillera (Figure 3). The event occurred near Malaga in 1680 with macroseismic magnitude of 6.2 should be reviewed since it is likely related to the intermediate depth earthquakes existing in the area. The 1829 Torrevieja and the 1884 Granada earthquakes are worth to be mentioned. The first one has a macroseismic magnitude of 6.3 , while that of the second is 6.1 (López Casado et al, 2000) and caused more than 800 fatalities (Martínez Solares, 2003). 
Table 1 Historical earthquakes with intensity equal to and larger than VII occurred in the Betic Cordillera. Data extracted from the catalogue edited by the National Geographic Institute, Madrid

\begin{tabular}{|c|c|c|c|c|c|c|}
\hline Location & $\begin{array}{c}\text { Date } \\
\text { a-mo-d }\end{array}$ & Time & Longitude & Latitude & Intensity & $m_{\mathrm{b}}{ }^{1}$ \\
\hline Vera (AL) & 1406 & & -1.87 & 37.25 & VII & 4.6 \\
\hline Granada & $1431-04-24$ & 14:00:00 & -3.63 & 37.13 & VIII-IX* & 5.0 \\
\hline Orihuela (A) & $1482-10-10$ & & -0.92 & 38.08 & VIII & 5.0 \\
\hline Almería & $1487-11$ & & -2.47 & 36.83 & VIII & 5.0 \\
\hline Málaga & $1494-01-26$ & 20:00:00 & -4.33 & 36.58 & VIII & 5.0 \\
\hline Carmona (SE) & $1504-04-05$ & 09:00:00 & -5.47 & 37.38 & VIII-IX* & 5.0 \\
\hline Vera (AL) & 1518-11-09 & $23: 30: 00$ & -1.87 & 37.23 & VIII & 5.0 \\
\hline Alhama de Almería (AL) & $1522-09-22$ & 10:00:00 & -2.67 & 36.97 & VIII-IX* & 5.0 \\
\hline Granada & $1526-07-04$ & $23: 00: 00$ & -3.57 & 37.18 & VII & 4.6 \\
\hline Baza (GR) & $1531-09-03$ & 4:00:00 & -2.73 & 37.53 & VIII & 5.0 \\
\hline Concentaina (A) & $1547-08-29$ & 20:00:00 & -0.43 & 38.75 & VII & 4.6 \\
\hline Lorca (MU) & $1579-01-03$ & & -1.70 & 37.68 & VII & 4.6 \\
\hline Málaga & $1581-06-18$ & 07:30:00 & -4.42 & 36.72 & VII & 4.6 \\
\hline Oliva (V) & $1598-12-26$ & 03:00:00 & -0.12 & 38.92 & VII & 4.6 \\
\hline Alcoy (A) & $1620-12-02$ & 19:00:00 & -0.47 & 38.70 & VII & 4.6 \\
\hline Muro de Alcoy (A) & 1644-06-19 & 18:00:00 & -0.42 & 38.80 & VIII & 5.0 \\
\hline Almería & $1658-12-31$ & 07:00:00 & -2.47 & 36.83 & VIII & 5.0 \\
\hline Orihuela (A) & $1673-01-15$ & & -0.92 & 38.08 & VIII & 5.0 \\
\hline Lorca (MU) & $1674-08-28$ & $21: 30: 00$ & -1.70 & 37.68 & VIII & 5.0 \\
\hline Málaga & $1680-10-09$ & 07:00:00 & -4.60 & 36.80 & VIII-IX & 6.2 \\
\hline Murcia & 1743-03-09 & $16: 00: 00$ & -1.13 & 38.00 & VII & 4.6 \\
\hline Estubeny (V) & $1748-03-23$ & 06:30:00 & -0.63 & 39.03 & IX & 5.6 \\
\hline Dalías (AL) & $1804-08-25$ & $08: 25: 00$ & -2.83 & 36.77 & VIII-IX* & 5.0 \\
\hline Pinos Puente (GR) & $1806-10-27$ & $12: 30: 00$ & -3.73 & 37.23 & VIII & 5.0 \\
\hline Torrevieja (A) & $1828-09-15$ & $05: 16: 00$ & -0.70 & 38.00 & VII & 4.6 \\
\hline Torrevieja (A) & $1829-03-21$ & 18:39:00 & -0.68 & 38.08 & IX-X & 6.3 \\
\hline Villanueva de S. Juan (SE) & $1862-08-22$ & 17:00:00 & -5.17 & 37.05 & VII & 4.6 \\
\hline Carlet (V) & $1872-05-19$ & $17: 15: 00$ & -0.52 & 39.23 & VII & 4.6 \\
\hline Arenas del Rey (GR) & $1884-12-25$ & 21:08:00 & -3.98 & 37.00 & IX-X & 6.1 \\
\hline Nacimiento (AL) & $1894-06-11$ & 03:30:00 & -2.67 & 37.12 & VII & 4.6 \\
\hline Grazalema (CA) & $1901-02-10$ & & -5.37 & 36.75 & VII & 4.6 \\
\hline Motril (GR) & $1901-05-25$ & 03:25:00 & -3.50 & 36.70 & VII & 4.6 \\
\hline Totana (MU) & $1907-04-16$ & $17: 30: 00$ & -1.50 & 37.80 & VII & 4.6 \\
\hline Ojos (MU) & 1908-09-29 & & -1.30 & 38.10 & VII & 4.6 \\
\hline Torrevieja (A) & 1909-07-01 & $14: 12: 18$ & -0.67 & 38.00 & VII & 4.6 \\
\hline
\end{tabular}

Note: Superscript ' 1 ' means that the result is from López Casado et al (2000); and superscript '*' means that the result is from Mézcua et al (2004). The magnitude of an event that has assigned two intensities was calculated using the smallest of them. In the column of "location", the letters in brackets are the initials of the provinces.

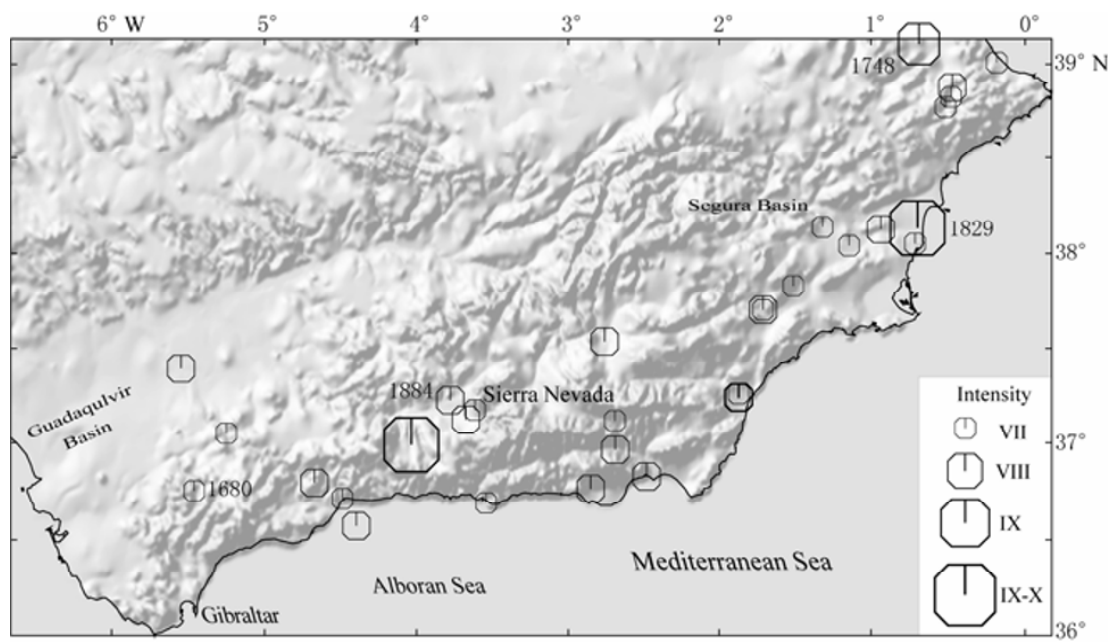

Figure 3 Most energetic historical earthquakes occurred along the Betic Cordillera. The dates 1748, 1829 and 1884 correspond to the Valencia, Torrevieja and Alhama de Granada earthquakes, with $m_{\mathrm{b}}$ magnitudes 5.6, 6.3 and 6.1, respectively (López Casado et al, 2000). The 1680 Malaga earthquake with magnitude 6.2 (López Casado et al, 2000) has been associated to a deep source. 


\section{Data}

\subsection{Earthquakes}

The database here used is the earthquake catalogue made by Mézcua and Solares (1983) after its last updating in 2009, whose edition is to charge of the National Geographic Institute in Madrid. The reliability, homogeneity and completeness of the reported data were previously tested. A posteriori there were not significant influences as to the robustness of the fractal dimension calculation. To calculate both the seismicity parameters and fractal dimensions it is really useful to have a large number of earthquakes. Also, to carry out a correct seismotectonic characterization of the study area it is advisable to work within the longer time period that is possible. So, a set of shallow earthquakes $(h \leq 30 \mathrm{~km})$ with $m_{\mathrm{bLg}}$ magnitude (based on the maximum amplitude of the $\mathrm{Lg}$ wave) $\geq 3.5$ occurred between 1910 and 2009 were selected. Foreshocks, aftershocks and swarms were discarded and only main shocks were included in the dataset. Figure 4 shows the spatial distribution of events in the Betic Cordillera under these constraints.

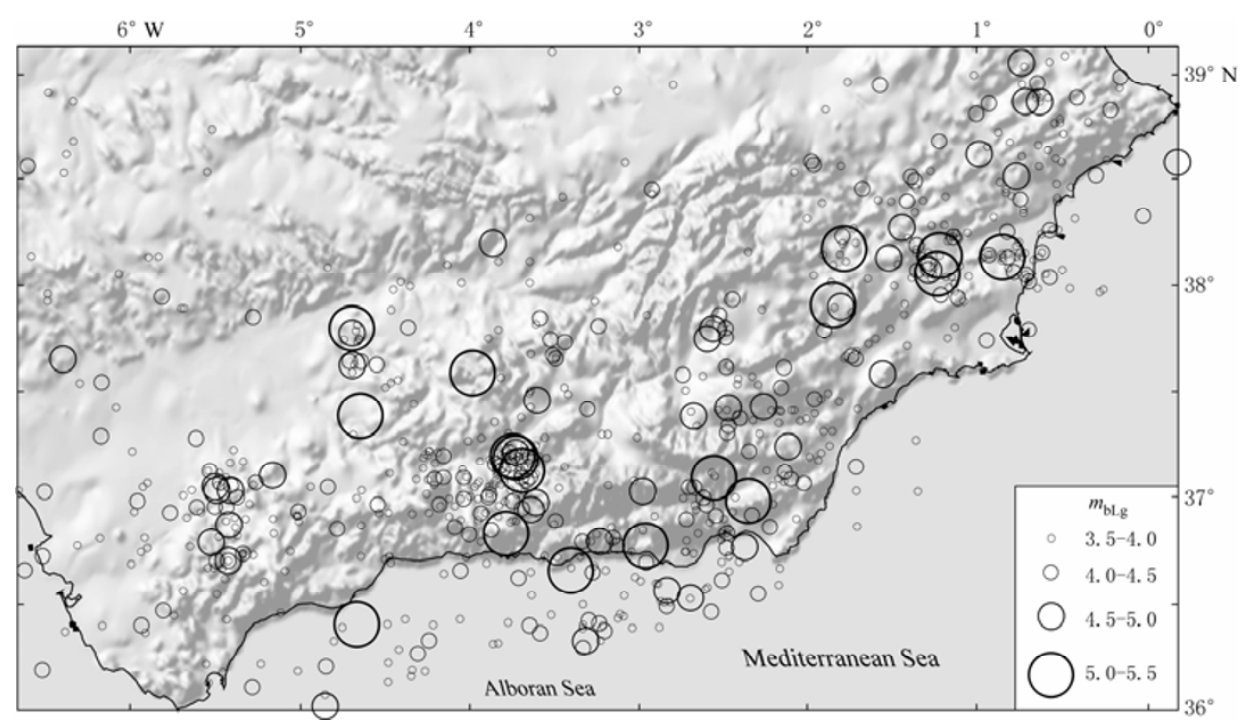

Figure 4 Epicentral distribution of shallow $(h \leq 30 \mathrm{~km})$ earthquakes with $m_{\mathrm{bLg}}$ magnitude from 3.5 to 5.2 occurred between 1910 and 2009.

\subsection{Faults}

To carry out fractal analysis it is necessary to approach every fault crossing the investigated region by a discrete set of points. So, the faults initially drawn as continuous lines on a map of the whole Iberian Peninsula at scale 1:200 000 (Figure 2), edited as a technical publication by the M.O.P.T. in 1992, were properly digitized and converted to equally-spaced 'point events' on the base of the scale used and the minimum distance between two near points $(100-150 \mathrm{~m})$ that can be appreciated on the map. In order to reduce possible digitization errors as far as possible, that distance was set in $200 \mathrm{~m}$. This means that at the worst case the smallest fault would be $200 \mathrm{~m}$ long and would be imaged by only two extreme points at the beginning and the end of it.

\section{Estimating fractal dimensions}

\subsection{Theory}

The multi-fractal analysis of a measure can be made through the generalized partition function proposed by Falconer (1990):

$$
\Phi(q, \tau)=E\left(\sum_{i=1}^{N} p_{i}^{q} \varepsilon_{i}^{-\tau}\right),
$$

where $q$ and $\tau$ are real numbers and $p_{i}$ represents the measure made with respect to a partition size of $\varepsilon_{i}$ (both random quantities). The sum extends over all the separated parts (up to $N$ ) with measure $p_{i}$ and size $\varepsilon_{i}$ which form the whole partition. Here $E$ denotes average value. Mathematically, the function $\Phi$ represents the $q$-moment of the measure coupled with the $\tau$-moment of the size.

If all parts have a same size $\varepsilon$, we directly obtain

$$
E\left\{\sum_{i=1}^{N} p_{i}^{q}\right\} \sim \mathcal{E}^{\tau}
$$

From this expression we can introduce the so-called partition function

$$
Z_{q}(\varepsilon)=\sum_{i=1}^{N(\varepsilon)} p_{i}^{q}(\varepsilon)
$$


The fixed-size box-counting algorithm is based on this expression that allows calculating $\tau(q)$ when taking logarithms on both sides of the equation

$$
\tau(q)=\lim _{\varepsilon \rightarrow 0} \frac{\log _{10} E\left(Z_{q}(\varepsilon)\right)}{\log _{10} \varepsilon} .
$$

The multi-fractal behavior of the measure $p_{i}$ inside a box of fixed size $\varepsilon$ and for a given real number $q$ comes expressed by $\tau(q)$. This limit cannot be reached through computational calculation, and so to solve this problem it is necessary to discretize and make a log-log linear fit. To accomplish this, the object is covered by a mesh of size $\varepsilon$ and the measures $p_{i}(\varepsilon)$ contained within each box of the mesh are calculated. To carry out the average required by the partition equation, the procedure is repeated several times changing the size $\varepsilon$ of the boxes. The slope of the log-log linear fit gives us the corresponding multi-fractal index.

The generalized dimension is determined through the expression introduced by Grassberger (1983) and Hentschel and Procaccia (1983)

$$
D_{q}=\frac{\tau(q)}{(q-1)}
$$

As the value given to $q$ varies $\left(q_{1}, q_{2}, q_{3} \ldots\right)$ we obtain different values of the multi-fractal index $\tau(q)$ and hence different values of the fractal dimension $D_{q}$.

A system is considered to be monofractal (Figure 5) when the generalized dimensions satisfy the equality ... $D_{q 1}=D_{q 2}=D_{q 3} \ldots$ for $\ldots q_{1}<q_{2}<q_{3} \ldots$ On the contrary, a system is considered to be multi-fractal (Figure 5) when those dimensions satisfy the inequality $\ldots D_{q 1}>$ $D_{q 2}>D_{q 3} \ldots$ for $\ldots q_{1}<q_{2}<q_{3} \ldots$ (Teotia, 2000). Regardless the value of $q$, the more dispersed is a system, the greater is the value of $D_{q}$, while those systems that

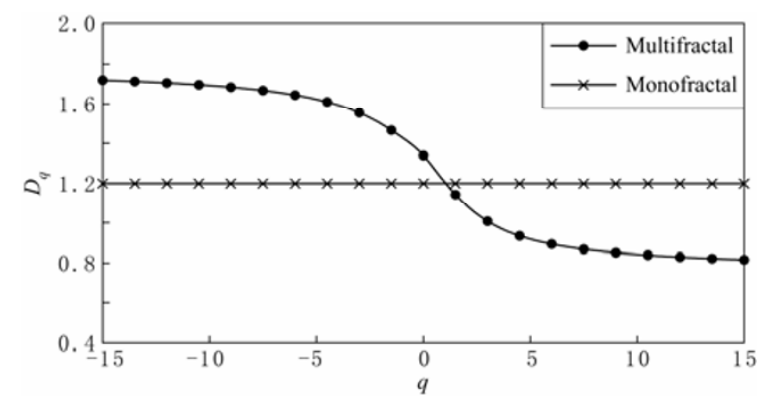

Figure 5 Different fractal behaviors: monofractal (crosses) when the generalized dimensions have similar values and multi-fractal (points) if these dimensions satisfy the relation $\ldots D_{q 1}>D_{q 2}>D_{q 3} \ldots$ for $\ldots q_{1}<q_{2}<q_{3} \ldots$. are more compact will have lower values of $D_{q}$ (Öncel and Wilson, 2006).

The spectrum of $D_{q}$ presents an asymptotic behavior when the $q$-value tends to $-\infty$ or $+\infty$, and the fractal dimensions $D_{-\infty}$ and $D_{+\infty}$ are respectively linked to the smallest and greatest values of the measurement (Martínez López et al, 2001). In this way, the slope of the multi-fractal spectrum, i.e. the difference between those two extreme generalized dimensions $\left(D_{-\infty}-D_{+\infty}\right)$, indicates whether the system is more or less homogeneous (Li et al, 1994). A quasi-homogeneous system presents a small slope or difference between extreme fractal dimensions. This is in correspondence with those regions where the seismicity (number of earthquakes) is rather sparse or the difference of energy released by ones and other events is small. If there were a characteristic earthquake with energy much greater than that of others, then the seismic region would be more heterogeneous that in the case of various earthquakes all of them with the same or similar energy. An analogous interpretation is valid for the faults, provided that their spatial distribution is the physical parameter considered.

The method presents a limitation when $q \rightarrow-\infty$ because the errors in the fractal dimensions are large when considering the position of the earthquakes and faults; it does not happen so with the energy. Despite this, several studies have shown that the jump of the multi-fractal spectrum is valid to characterize the spatial distribution of seismicity and its possible relation to the stress field (Li et al, 1994; Dimri, 2000; Carpinteri et al, 2002). Other works considered the difference $D_{2}-D_{+\infty}$ (Shivakumar and Rao, 2000; Öncel and Wilson, 2006). However, the difference $D_{-\infty}-D_{+\infty}$ is the one between subsets of small and large measurements and it reflects the heterogeneity of the investigated object. With the difference $D_{2}-D_{+\infty}$ we have found that the results obtained are not the same that if we use $D_{-\infty}-D_{+\infty}$. Nevertheless, the multi-fractal spectrum has an asymptotic behavior for large values of $|q|$ as for example $|q|=6$ (Teotia, 2000), $|q|=10$ (Shivakumar and Rao, 2000) or $|q|=$ 15 (Öncel and Wilson, 2006). We have worked with $|q|$ $=30$ and the difference $D_{-30}-D_{+30}$ as these choices allow a more detailed analysis of the variations of the multi-fractal spectrum (especially with the energy).

\subsection{Implementation}

It is assumed that the earthquake catalogue is complete from a minimum magnitude $m_{\mathrm{o}}$ and every earthquake can be regarded as a random sample from a pop- 
ulation whose magnitude distribution takes the form as given by the Gutenberg-Richter empirical formula (Gutenberg and Richter, 1944). We follow the method proposed by Utsu (1965) and Aki (1965) to determine the $b$-value of the Gutenberg-Richter lineal relationship and we specifically start from the expression (Utsu, 1966, 1967)

$$
\frac{1}{\beta} \frac{\beta \delta}{\tanh (\beta \delta)}=\bar{m}-m_{\mathrm{o}}
$$

where $\delta$ is $1 / 2$ of the length of the equivalence class which are being considered, $\bar{m}$ is the average magnitude and $\beta$ is equal to $b \ln 10$.

The multi-fractal analysis of the seismicity is based on the number and position of the earthquakes and the released seismic energy, which is determined by the expression

$$
\log _{10} E=3.5+3.0 \cdot m_{\mathrm{bLg}}
$$

derived from the relationship between the energy $E$ and the magnitude $m_{\mathrm{b}}$ (Gutenberg and Richter, 1956) combined with the relation between $m_{\mathrm{bLg}}$ and $m_{\mathrm{b}}$ valid within the interval $[2.5,6.0]$ for the south of the peninsula and north of Morocco (Henares Romero, 2009).

The analysis is performed with the help of a $(100 \mathrm{~km} \times 100 \mathrm{~km})$-sized moving spatial window that is sequentially shifted east-to-west and north-to-south at a constant step of $20 \mathrm{~km}$ along the Betic Cordillera. Within this window in a certain position we consider $(1 \mathrm{~km} \times 1 \mathrm{~km})$-sized boxes. This mesh size establishes the lower limit of the range wherein the fractal properties of the data points inside a box are determined, while the upper limit comes defined in each case by the greatest distance between data points found inside that box (Kagan and Knopoff, 1980). This same approach (boxes of fixed size $1 \mathrm{~km} \times 1 \mathrm{~km}$ ) has been used with earthquakes and faults. From all data points belonging to a same box, we calculate the $b$-value (indicative of the magnitude-frequency relationship of earthquake occurrence) and the respective fractal dimension $D_{q}$ (for a given real number $q$ ) with relation to epicentral locations, seismic energies and faults (depending on the case), and after the multi-fractal spectrum slope (for $q$-values from -30 to +30) using the fixed-size box-counting algorithm implemented by Martínez López et al (2001). The value of this specific parameter (slope) is always assigned to the middle point of the box. These operations are repeated for different partitions of the study area once the moving window is shifted $20 \mathrm{~km}$ over it. The last step consists in a mapping of the results (slopes) by contour lines using a smoothing algorithm.

\section{Results}

The spectra obtained from the analysis of the earthquakes and faults in the Betic Cordillera show an evident multi-fractal behavior of both datasets (Figure 6). This key result supports the idea of finding heterogeneous patterns as to the spatial distribution of earthquakes and faults.
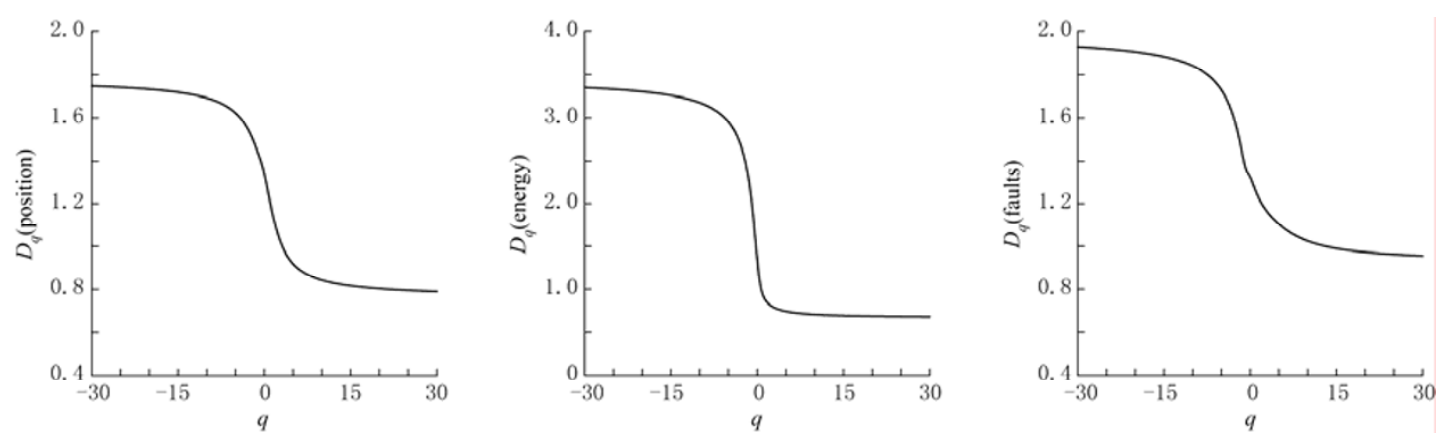

Figure 6 Multi-fractal spectra related to earthquakes and faults in the Betic Cordillera obtained from location and energy measurements in one case and faulting in other. The multi-fractal character of any spatial distribution of data is evident.

Figure 7 shows the spatial variation of the $b$-value ranging from 0.8 to 1.4 , with an approximated average value of 1.1 that is typical of areas of moderate seismic activity (López Casado et al, 1995; Molina, 1998; Peláez, 2000; Peláez and López Casado, 2002). The western and middle parts of the Betic Cordillera and a small area nearby Alicante present $b$-values above the average value, while a wide extension covering most of the eastern zones of the cordillera shows $b$-values below 1.1. The maximum $b$-values close to 1.4 are encountered on the westernmost segment of the mountain range (south of Ubrique) and the minimum ones, close to 0.9 , 
on the eastern half.

The spatial variation of the multi-fractal spectrum slope as derived from the geographical locations of the earthquakes is shown in Figure 8. The map does reveal the grade of heterogeneity affecting the distribution of shallow earthquake epicenters in the Betic Cordillera
(Figure 4). The western half of the Betic Cordillera, integrated by two areas clearly differentiated from the rest, is the one with a higher heterogeneity in this sense. The easternmost part of the cordillera, with a less extension, has also a certain grade of heterogeneity with respect to epicentral locations.

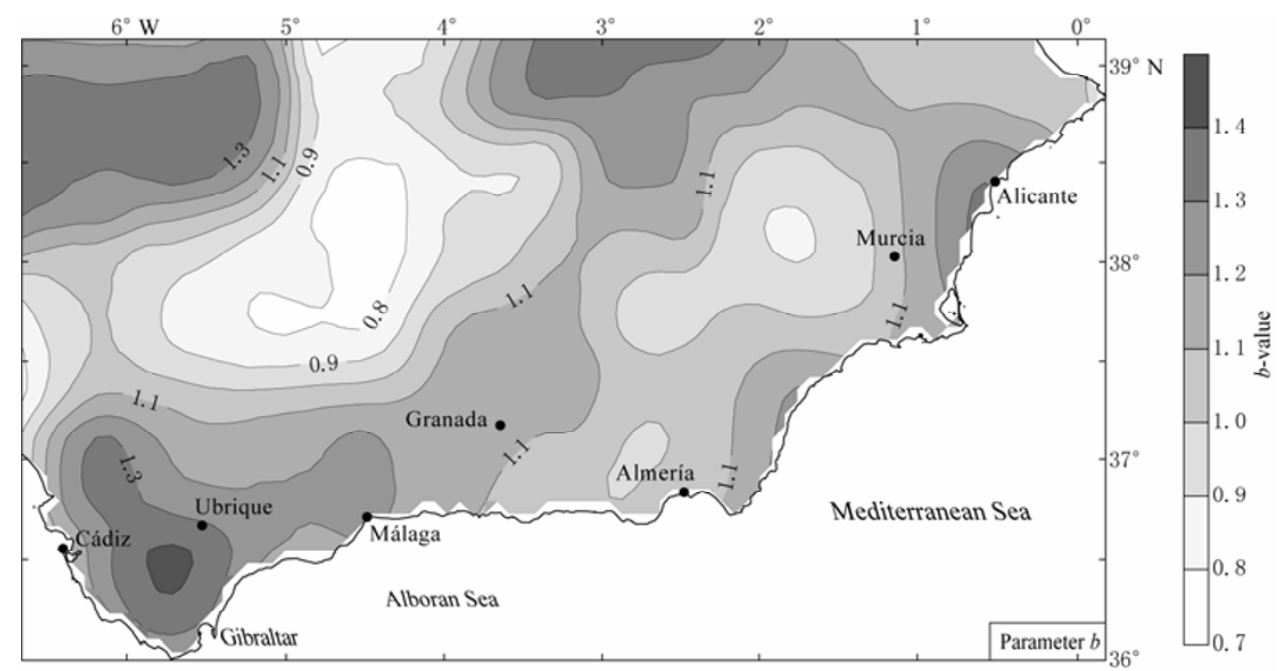

Figure 7 Spatial variation of the $b$-value estimated using the Utsu's method (Utsu, 1965) with a (100 km $\times 100 \mathrm{~km})$ -sized moving spatial window that is sequentially shifted $20 \mathrm{~km}$ along the Betic Cordillera.

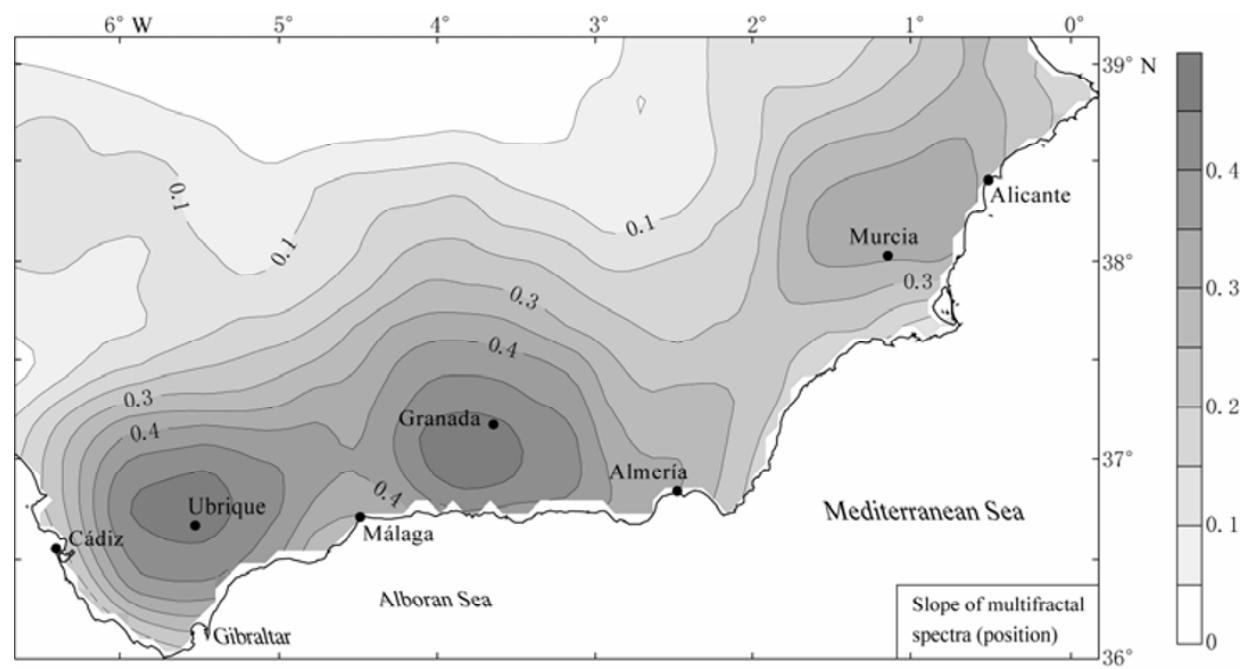

Figure 8 Spatial variation of the multi-fractal spectrum slope based on earthquake locations. Low values are associated to homogeneous zones while high ones depict spatially heterogeneous zones in terms of seismicity.

The spatial variation of the difference between the fractal dimensions $D_{-\infty}$ and $D_{\infty}$ once calculated taking the energy released by the earthquakes as parameter of reference is shown in Figure 9. A clearly differentiated high-value zone located to the east around Alicante reveals a heterogeneous distribution of the energy. Although not as well defined spatially, other region with similarly high values can be encountered between Granada and Jaen on the middle third of the Betic Cordillera. Both zones are separated by an area with lower values focused on the Sierra Nevada mountain range. There is yet another zone along the coast of Malaga that also presents a high heterogeneity from the viewpoint of the energy released by the regional earthquakes. As can be 
seen, the most energetic earthquakes of the Betics (Table 1, Figure 3) have taken place within the most heterogeneous areas on the map.

Lastly, the degree of heterogeneity of the fault systems (Figure 2) can be viewed through the spatial variation of the difference between the generalized dimensions $D_{-\infty}$ and $D_{\infty}$ when the digitized faulting is taken as parameter of reference. Figure 10 shows this information. In this case, the zone with a more heterogeneous distribution of faults lies clearly along a broad band over the east part of the Betics, being the less heterogeneous and uneven zone over the western one. The results for the north-northwest area have been calculated using a limited dataset by which they could be subject to error and therefore somewhat biased; such area has been excluded from this analysis. Owing to the procedure used for drawing the illustrations, the values plotted in Figures 8, 9 and 10 are all a bit smoothed.

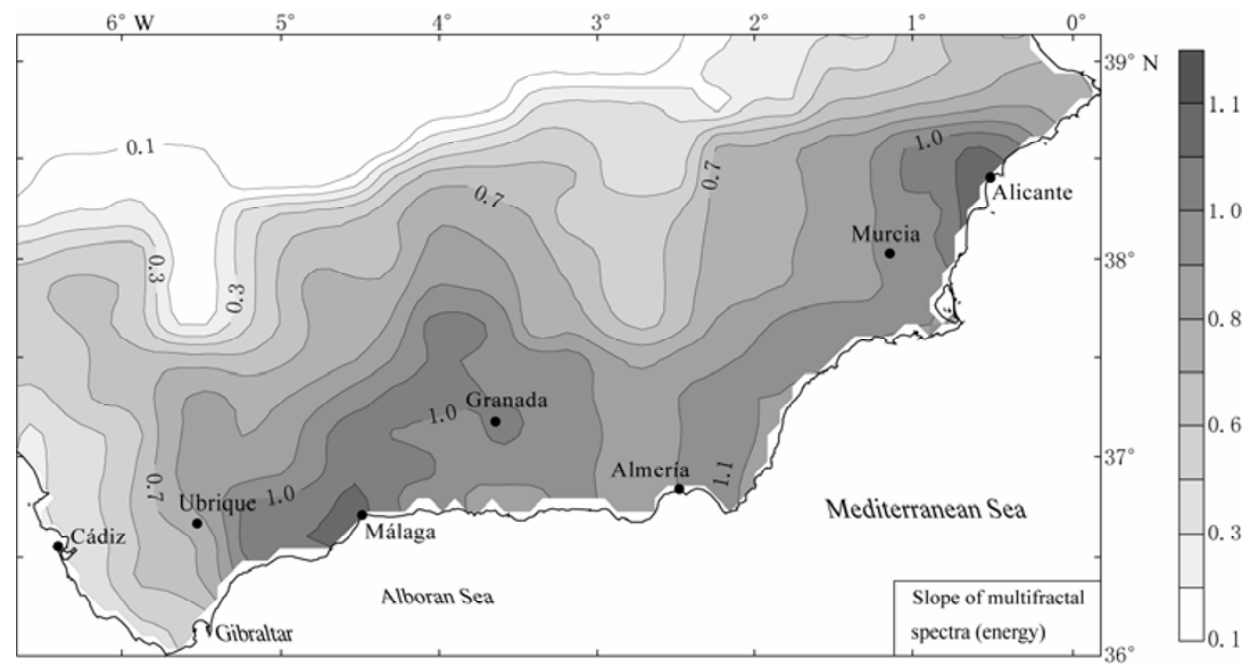

Figure 9 Spatial variation of the multi-fractal spectrum slope obtained using the energy released by the earthquakes. As before, low values correspond to homogeneous zones and high ones to spatially heterogeneous zones in terms of seismic energy.

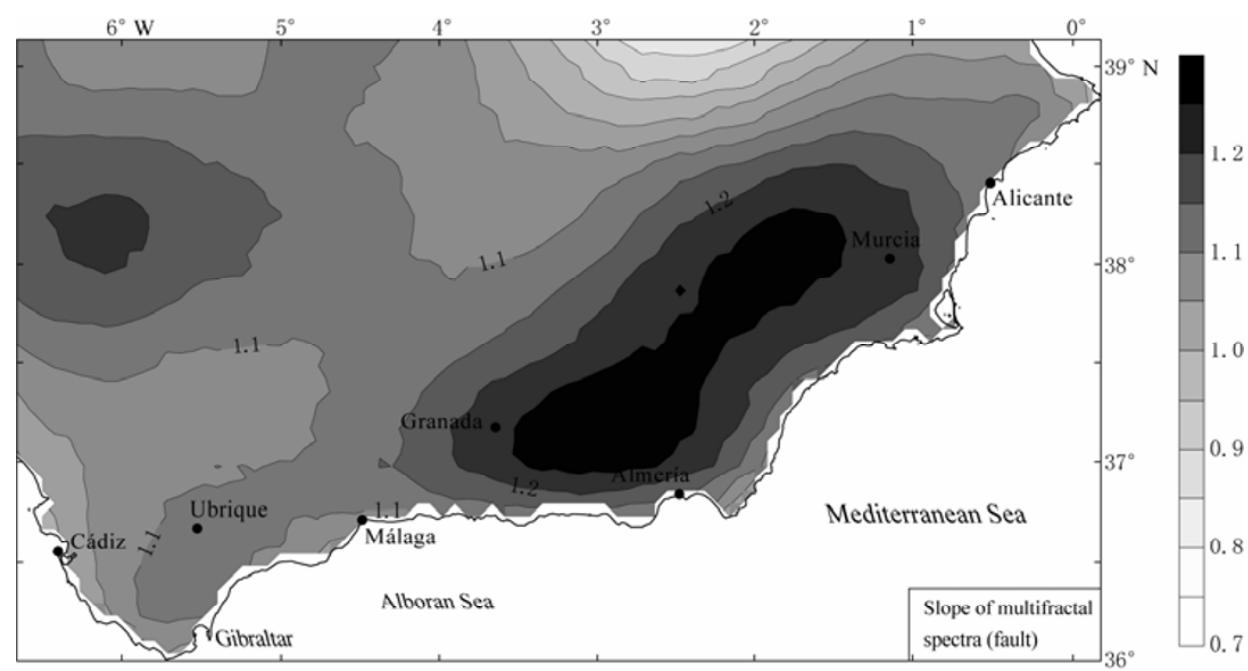

Figure 10 Spatial variation of the multi-fractal spectrum slope based on faulting. Analogously, low values are indicative of homogeneous zones and high ones of zones with a spatially heterogeneous distribution of faults.

\section{Discussion}

\subsection{About the size of the moving window}

In a principle, Smith (1988) suggested that it takes a large number of data sets to estimate the fractal dimension $D$ accurately. Although there is also evidence that much smaller data sets are adequate if the estimation of the variation in fractal dimension is more impor- 
tant than its absolute value (Narenberg and Essex, 1990) According to Utsu (1965), when the number of events used for the estimation exceeds 50, the maximum likelihood method gives a stable estimation of the $b$-value. $\mathrm{Xu}$ and Burton (1999) proposed a minimum of 42 earthquakes for the calculation of the dimension with the Grassberger-Procaccia algorithm, and Bhattacharya and Kayal (2003) reduced this number to 20 earthquakes inside each sample. More recently, Singh et al (2008, 2009) have considered a minimum of 50 earthquakes for the calculation of the $b$-value and the fractal dimension. Keeping this in mind we have taken a (100 $\mathrm{km} \times 100$ $\mathrm{km}$ )-sized moving window, so that the number of data within it to calculate the parameter $b$ and the fractal spectrum exceeds the value 40 in most cases. So we make sure that the information amount is always enough. On the other hand, if we take a larger window the consequence is an undesirable smoothing of the results.

\subsection{On the results}

The present research has revealed that the difference between $D_{-\infty}$ and $D_{\infty}$ in the study of seismicity is more significant when using the earthquake energy as parameter of reference (2.67) instead of its position (0.96) (Figure 6). Results achieved using both the earthquake energy and position as measurement parameters are similar to those obtained by Hirabayashi et al (1992) when studying the earthquakes of California, Japan and Greece and by Carpinteri et al (2002) for the earthquakes of Italy. The difference between $D_{-\infty}$ and $D_{\infty}$ in the case of geological fault systems $(0.98)$ is however similar to that obtained using earthquake locations (Figure 6). This and no other is the expected result taking into account that throughout a complete seismic cycle the space occupied by the earthquakes should match with the space occupied by the faults that cause them. Therefore, both earthquakes and faults of the Betic Cordillera have a heterogeneous structure, and this heterogeneity is even more significant regarding the seismic energy whose origins are the faults. The geodynamic process of the Betics is so much more complex than what might be expected at first.

A variation in the $b$-value can be attributed to changes in the stress distribution (Scholz, 1968). Main et al (1990) found a relation between the $b$-value and the stress such that when the former decreases the latter increases. Bearing this in mind and too the $b$-value map (Figure 7), it is possible to infer that the eastern part of the Betics is the zone where there is a higher accumulation of tectonic stresses.
The spatial variation of the multi-fractal spectrum slope supplied by earthquake locations (Figure 8) permits to distinguish between the heterogeneity of the eastern third of the Betics and that of the middle and western thirds. Despite the similarities between these two last thirds are remarkable, their behaviors differ each other depending on the $b$-value (Figure 7 ) and the historical seismicity (Figure 3). The differences between the middle third (Granada) and the eastern third (Alicante) of the Betics are worthy to be stressed. These two areas have not a very different historical seismicity (Figure 3); however, they still show a differentiated behavior with respect to the $b$-value (Figure 7) whose explanation could find in that the seismotectonic properties of the middle third are more similar to those of the western third than to those of the eastern one. On this issue we shall return later.

The spatial variation of the multi-fractal spectrum slope when the seismic energy is taken as measurement parameter (Figure 9) defines two large zones of maximum values: one covers the mid-western region of the Betics and the other the eastern third. However, the central part of the mid-western region (near Granada), which was before clearly defined by the spectral slope based on the earthquake position as parameter of reference (Figure 8), now appears imprecise or blurred. There is still an ill-defined subzone that could be associated to the historical 1884 Arenas del Rey (Granada) earthquake (Figure 3). The two subzones of maximum values are located in Malaga and Alicante (Figure 9) in concordance with the historical earthquakes occurred in 1680 and 1829 (Figure 3). This result is also worthy to be stressed because after considering the instrumental earthquakes occurred during the last 100 years and obtaining the multi-fractal spectrum slope using the energy of seismic origin, it has been possible to delineate the three zones where the most destructive earthquakes in the Betics have occurred.

The spatial variation of the multi-fractal spectrum slope determined from geological fault systems (Figure 10) shows an eastern zone clearly differentiated by high values and a mid-western zone with comparatively lower values which remains unclear. The high-value area stretches from Sierra Nevada (Granada) to the Segura River basin (Murcia) and is flanked by instrumental and historical events of relatively great magnitude (Figures 3 and 4). In the north part there have been two instrumental earthquakes of magnitude 5.0 (Figure 4). To the northwest a part with high values too is associated to old 
faults of more than two millions of years nowadays without seismic activity. Consequently, it may be agreed that the most energetic earthquakes do not necessarily happen in the most spatially heterogeneous regions.

Regardless the type of measurement parameter taken into consideration, either distribution of earthquake epicenters or faults (Figures 8 and 10), the zone nearer to Malaga, where the 1680 earthquake occurred (Figure 3), is particularly striking according to the multi-fractal analysis based on the energy of the earthquakes (Figure 9) The maximum value obtained would indicate that the zone is seismically active with events of certain magnitude where there is a predominant earthquake whose energy is over that of the others. Malaga presents a rather homogeneous pattern against other adjacent zones when considering the position of epicenters (Figure 8) or faults (Figure 10). On the contrary, it exhibits a higher degree of heterogeneity when the energy of the earthquakes is taken as measuring parameter (Figure 9). This result could be possibly related to the seismogenetic focus at intermediate depth located south of Malaga. Consequently, the seismicity of the region would be more influenced by events at intermediate depth, in spite of being a more homogeneous area in terms of position of the earthquakes (at depths $\leq 30 \mathrm{~km}$ ) and faults.

\subsection{Seismotectonic zonation and stress field}

Leaving aside that the exact boundaries are difficult to establish, two large seismotectonic regions can be delimited, namely: zone 1 which extends SW-NE and covers roughly the eastern third of the Betic Cordillera, and zone 2 which extends WSW-ENE and covers the mid-western part (Figure 11). The previous analyses from earthquake epicenters (Figure 8) and seismic energy (Figure 9) depict both zones that are clearly separated by Sierra Nevada. Each of these seismotectonic regions allows the distinction of other subzones. Thus, the Murcia-Alicante subzone, where the values obtained tend to be somewhat lower in the surroundings of Murcia but higher in the environs of Alicante, would be within zone 1 . Two smaller regions belonging to zone 2 would be in the middle third of the Betics around Granada and the westernmost zone around Ubrique, separated one from other by the seismicity at intermediate depth near Malaga (Figure 11). The Murcia-Alicante subzone (more specifically the area to south of Murcia) reveals a lower degree of heterogeneity when compared to the subregions to both sides of Malaga, whenever the earthquake position is the parameter taken into consideration; although a sharper feature of homogeneity if the earthquake energy is the parameter of reference. This discrepancy may be associated to the local stress and its different accumulation.

Under a regional compression stress field of NW-SE trend affecting the Ibero-Maghrebian contact, there exist other local stress states of N-S compression in the zone 1 and ENE-WSW tension in the zone 2

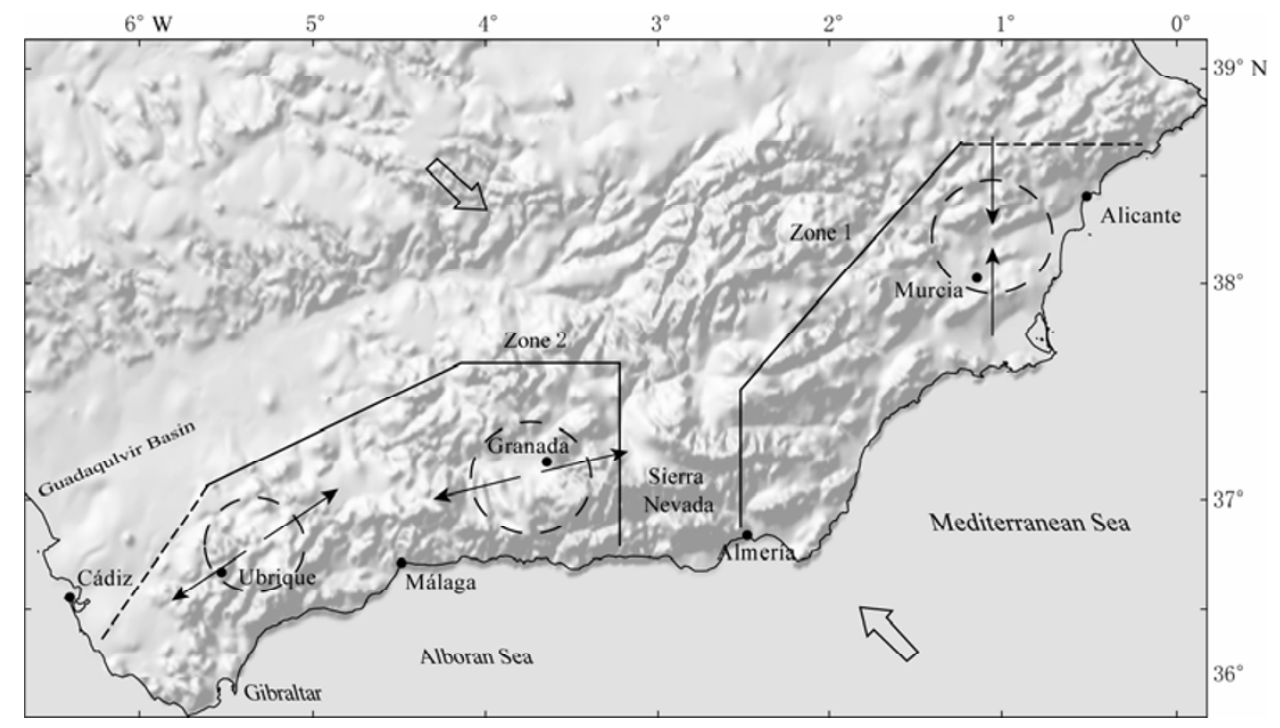

Figure 11 Seismotectonic zones in the Betic Cordillera delimited by the slopes of the multi-fractal spectra obtained after using earthquakes and faults data together with the $b$-values. Black arrows represent local stresses (Henares et al, 2003) and the white ones the NW-SE stresses affecting the junction of the Ibero-Maghrebian region (Buforn et al, 1988b; Coca and Buforn, 1994; Buforn et al, 1995; Mézcua, 1997; Proyecto Sigma, 1998; Herráiz, 2000; Henares et al, 2003). 
(Henares et al, 2003). The regional stress field can be nicely identified as follows: (1) NE-SW tension in Ubrique; (2) WNW-ESE compression in Malaga that might be related to the arc-shaped distribution of intermediate earthquakes existing south of this city; (3) ENE-WSW tension (and other secondary NNW-SSE depicting a radial pattern) in Granada; (4) N-S compression in Alicante. $\mathrm{Xu}$ and Burton (1999) reported that the coexistence of two different stress fields in a same region (central Greece), interacting with variable seismicity, could explain the relatively low intensity of the stresses (high $b$-value). This phenomenon may have happened in zone 2 (dominated by extension) with a less stress accumulation, making it more heterogeneous than zone 1 (dominated by compression) that is subjected to local stresses of similar direction. A similar conclusion can be extracted from the results for Eastern Himalaya and Southern Tibet obtained by Singh et al (2009). According to these authors, high values of the correlation dimension and the parameter $b$ (as it happens in zone 2) could be indicative of a heterogeneous structure, while low values of $b$ (as it happens in zone 1) could be the expression of a great accumulation of stresses.

Furthermore, the subzones of Granada and Ubrique (under tension) have a spatial distribution of earthquakes more heterogeneous than Malaga and the Murcia-Alicante subzone (under compression) (Figure 8), being this latter less heterogeneous territorially than the two first in terms of generation of energy (Figure 9). That is, in Malaga and Alicante the energy is released in a more concentrated way, particularly in Malaga where already there was an energetically predominant earthquake over the others (Figure 3), while in Granada and Ubrique and in points around these cities many earthquakes of similar energy occur. Therefore, the seismotectonic characteristics of the middle third of the Betics prove to be more similar to those of the western third than to those of the eastern third, as expected according to the local stresses.

\subsection{Seismotectonic and geodynamical evolution}

Giaquinta et al (1999) and Sherman and Gladkov (1999) have proved that a same faulting region subjected to different states of stress has different fractal geometry. Considering this, it can be thought that the zone defined by maximum values of the multi-fractal spectrum slope has followed a different geodynamical evolution, becoming a more heterogeneous region in which seismic events with magnitude greater than 5.0 do not happen usually.
It makes perfect sense to think that the results obtained from the fractal properties of the earthquakes are related to the heterogeneity due to faults and stresses. The results obtained by means of the analysis of faults should allow the differentiation of areas to either side of the maximum values observed. Considering that the faults represent a period of millions of years, it is very likely that the distribution of faults (active tectonic), besides being also the result of alternative periods of tension and compression (Sanz de Galdeano et al, 2010), is the reason of the geodynamical evolution of the Betic Cordillera. Hence the necessity of having at hand a more complete database of faults in order to study the different systems by separate.

\section{Conclusions}

The multi-fractal geometry has proved itself as an efficient instrument for the seismotectonic characterization of the Betic Cordillera to the extent that the regional seismicity shows fractal properties referred to its spatial distribution and energetic capacity. The fault systems which extend all over the cordillera have a multi-fractal character too. Both earthquakes and faults of the Betic Cordillera behave like heterogeneous systems, being this heterogeneity even more significant regarding the energy of seismic origin.

Seismically speaking, the eastern part of the Betics is comparatively less heterogeneous, but it is the zone where there is a higher accumulation of tectonic stresses (low $b$-values).

In relation to the seismic energy, the mid-western region near Granada and Ubrique appears as an area of almost permanent seismic activity and therefore producer of energy. Malaga and Alicante are the subzones in which maximum values are detected. However, the most energetic earthquakes do not necessarily take place in the most spatially heterogeneous regions. Malaga presents a rather homogeneous pattern against other adjacent zones when considering the position of epicenters or faults. On the contrary, it is highly heterogeneous in terms of seismic energy as it is associated to an energetically predominant earthquake in the past, possibly related to intermediate depth seismicity.

The seismotectonic zonation of the Betic Cordillera is justified by the fractal geometry of earthquakes and faults. Depending on the greater or lesser heterogeneity defined by the multi-fractal spectrum slope obtained from earthquake frequency, location and energy, two seismotectonic regions can be distinguished: one on the 
eastern third and other on the mid-western part of the mountain range. The seismic energy comes to be the parameter that better supports objectively such a partition, the more so the greater the time interval considered and the range of magnitudes. The difference in heterogeneity detected on these regions seems to keep relation with the different local stress states.

Moreover, the seismotectonic characteristics of the middle third of the Betics prove to be more similar to those of the western third than to those of the eastern third, as expected according to the local stresses.

Assuming that the spatial and energetic heterogeneity may be conditioned by local stresses, each type of stress should provoke a differentiated geodynamic behavior (released energy, fracture of the terrain, etc.) that should lead to a spatial and energetic pattern own of each subzone. Therefore, the fractal geometry proves to be a useful tool to distinguish areas with different seismicity and stress states. Future analyses with more complete catalogues of earthquakes will permit to explore this appealing possibility.

Acknowledgments We would like to thank Prof. Sanz de Galdeano for his assistance given in the course of this work. We also thank anonymous referees by their helpful comments and suggestions that led to a significant improvement of the early manuscript. The Ministry of Education and Science funded this study (project CGL2007-60535), which was also sponsored by the Junta de Andalucía, Spain, through the Research Groups RNM-217 and RNM-024.

\section{References}

Aki K (1965). Maximum likelihood estimate of $b$ in the formula $\log N=a-b M$ and its confidence limits. Bull Earthq Res Inst 43: 237-239.

Alfaro P, Rueda J, Delgado J, Estévez A, López Casado C and Giner J (1999). Seismotectonics of the lower Segura basin (Betic Cordillera). Proceedings of the 1st Hispano-Portuguese Assembly of Geodesy and Geophysics. University of Almeria and National Geographic Institute, Madrid (in Spanish).

Bhattacharya P M, Majumdar R K and Kayal J R (2002). Fractal dimension and $b$-value mapping in northeast India. Current Science 82(12): 1486-1491.

Bhattacharya P M and Kayal J R (2003). Mapping the $b$-value and its correlation with the fractal dimension in the northeast region of India. J Geol Soc India 62: 680-695.

Bezzeghoud M and Buforn E (1999). Source parameters of the 1992 Melilla (Spain, $M_{\mathrm{W}}=4.8$ ), 1994 Alhoceima (Morocco, $M_{\mathrm{W}}=5.8$ ) and 1994 Mascara (Algeria, $M_{\mathrm{W}}=4.7$ ) earthquakes and seismotectonic implications. Bull Seism Soc Amer 89(2): 359-372.

Buforn E, Udías A and Mézcua J (1988a). Seismicity and focal mechanisms in South Spain. Bull Seism Soc Amer 78(6): 2008-2024.

Buforn E, Udías A and Colombás M A (1988b). Seismicity, source mechanisms and tectonics of the Azores-Gibraltar plate boundary. Tectonophysics 152(1-2): 89-118.
Buforn E, Sanz de Galdeano C and Udías A (1995). Seismotectonics of the Ibero-Maghrebian region. Tectonophysics 248(3-4): 247-261.

Carpinteri A, Chiaia B and Invernizzi S (2002). Applications of fractal geometry and renormalization group to the Italian seismic activity. Chaos Solitons and Fractals 14(6): 917-928.

Coca P and Buforn E (1994). Focal mechanisms in South Spain: Period 1965-1985. Estudios Geológicos 50: 33-45 (in Spanish).

Cortés A L and Maestro A (1998). Recent intraplate stress field in the eastern Duero Basin (North Spain). Terra Nova 10(5): 287-294.

Dimri V P (2000). Application of fractals in seismology with reference to Koyna earthquakes. In: Dimri V P ed. Application of Fractals in Earth Sciences. A.A. Balkema, USA/Oxford, and IBH Pub. Co., New Delhi, pp. 139-147.

Falconer K J (1990). Fractal Geometry: Mathematical Foundations and Applications. John Wiley \& Sons, England, pp. 366.

Galindo-Zaldívar J, González Lodeiro F and Jabaloy A (1993). Stress and palaeostress in the Betic-Rif cordilleras (Miocene to the present). Tectonophysics 227(1-4): 105-126.

Giaquinta A, Boccaletti S, Boccaletti M, Piccardi L and Arecchi F T (1999). Investigating the fractal properties of geological fault systems: The main Ethiopian Rift case. Geophys Res Lett 26(11): 1 633-1 636.

Grassberger P (1983). Generalized dimensions of strange attractors. Phys Lett A 97(6): 227-231.

Grimison N and Chen W (1986). The Azores-Gibraltar plate boundary: Focal mechanisms, depths of earthquakes and their tectonic implications. $J$ Geophys Res 91(B2): 2029-2047.

Gutenberg B and Richter C F (1944). Frequency of earthquakes in California. Bull Seism Soc Amer 34(4): 185-188.

Gutenberg B and Richter C F (1956). Earthquake magnitude, intensity, energy, and acceleration. Bull Seism Soc Amer 46(2): 105-145.

Gutscher M A, Malod J, Rehault J P, Contrucci I, Klingelhoefer F, Mendes-Victor L and Spackman W (2002). Evidence for active subduction beneath Gibraltar. Geology 30(12): 1 071-1 074.

Hatzfeld D and Boloix M (1976). Preliminary results of deep seismic profiles in the Alboran Sea. Meeting on Geodynamics of the Betic Cordillera and Alboran Sea, Granada, Spain, pp. 19-23 (in Spanish).

Henares Romero J (2009). Multi-fractal characterization of the seismotectonic of the Betic Cordillera. [PhD Dissertation]. University of Granada, Spain, pp. 215 (in Spanish).

Henares J, López Casado C, Sanz de Galdeano C, Delgado J and Peláez J A (2003). Stress fields in the Ibero-Maghrebian region. J Seism 7(1): 65-78.

Hentschel H and Procaccia I (1983). The infinite number of generalized dimensions of fractals and strange attractors. Physica D 8(3): 435-444.

Hernández J, Larouzière F D, Bolze $\mathrm{J}$ and Bordet $\mathrm{P}$ (1987). The Neogene magmatism of the Betic-Rif complex and the slipping corridor of Alboran. Bull Soc Géol Fr 3(2): 257-267 (in French).

Herráiz M, De Vicente G, Lindo Naupari R, Giner J, Simón J L, González Casado J M, Vadillo O, Rodríguez-Pascua M A, Cicuéndez J I, Casas A, Cabañas L, Rincón P, Cortés A L, Ramírez M and Lucini M (2000). The recent (upper Miocene to Quaternary) and present tectonic stress distributions in the Iberian Peninsula. Tectonics 19(4): 762-786.

Hirabayashi T, Ito K and Yoshii T (1992). Multi-fractal analysis of earthquakes. Pageoph 138(4): 591-610.

Jolivet L, Faccenna C and Piromallo C (2009). From mantle to crust: Stretching the Mediterranean. Earth Planet Sci Lett 285(1-2): 198-209.

Kagan Y Y and Knopoff L (1980). Spatial distribution of earthquakes: The two point correlation function. J Geophys R Astron Soc 62(2): 303-320.

Li D, Zheng Z and Wang B (1994). Research into the multi-fractal earthquake spatial distribution. Tectonophysics 233(1-2): 91-97.

López Casado C, Sanz de Galdeano C, Delgado J and Peinado M A (1995). The $b$ parameter in the Betic Cordillera, Rif and nearby sectors: Relations with the tectonics of the region. Tectonophysics 248(3-4): 277-292.

López Casado C, Molina S, Giner J and Delgado J (2000). Magnitude-intensity relationships in the Ibero-Maghrebian region. Natural Hazards 22(3): 269-294.

López Casado C, Sanz de Galdeano C, Molina Palacios S and Henares Romero J (2001). The structure of the Alboran Sea: An interpretation from seis- 
mological and geological data. Tectonophysics 338(2): 79-95.

Main I G, Meredith P G, Sammonds P R and Jones C (1990). Influence of fractal flaw distributions of rock deformation in the brittle field. In: Knipe R J and Rutter E H eds. Deformation Mechanisms, Rheology and Tectonics. Geol Soc London Special Publication 54: 81-96.

Mandelbrot B B (1982). The Fractal Geometry of Nature. Freeman, San Francisco, pp. 468.

Mandelbrot B B (1989). Multi-fractal measures, especially for the geophysicist. Pageoph 131(1-2): 5-42.

Martínez Solares J M (2003). Historical seismicity of the Iberian Peninsula. Física de la Tierra 15: 13-28 (in Spanish).

Martínez López F, Cabrerizo Vilchez M A and Hidalgo Álvarez R (2001). Multi-fractal behaviour of the estimated natural measure for colloidal cluster-cluster aggregation in 2-D. Physica A 291(1-4): 1-12.

Medina F and Cherkaoui T E (1991). Focal mechanisms of the Atlas earthquakes and tectonic implications. Geologische Rundschau 80(3): 639-648.

Mézcua J and Martínez Solares J M (1983). Seismicity of the Ibero-Maghrebian area, National Geographic Institute, Madrid, Publ. 203, pp. 300 (in Spanish).

Mézcua J and Rueda J (1997). Seismological evidence for a delamination process in the lithosphere under the Alboran Sea. Geophys J Int 129(1): 256-264.

Mézcua J, Rueda J and García Blanco R M (2004). Reevaluation of historic earthquakes in Spain. Seism Res Lett 75(1): 75-81.

Molina S (1998). Seismotrctonics and seismic hazard of the contact area between Iberia and Africa. [PhD Dissertation]. University of Granada, Spain, pp. 288 (in Spanish)

M.O.P.T. (1992). Seismotrctonic Analysis of the Iberian Peninsula, Balearic and Canary Islands. Ed. National Geographic Institute, Madrid, Tech. Publ. 26 (in Spanish).

Morales J, Serrano I, Jabaloy A, Galindo-Zaldívar J, Zhao D, Torcal J, Vidal F and González Lodeiro F (1999). Active continental subduction beneath the Betic Cordillera and the Alboran Sea. Geology 27(8): 735-738.

Moreira V S (1985). Seismotectonics of Portugal and its adjacent area in the Atlantic, Tectonophysics 117(1-2): 85-96.

Narenberg M A H and Essex C (1990). Correlation dimension and systematic geometric effects. Phys Rev A 42(12): 7065-7074.

Öncel A O, Wilson T H and Nishizawa O (2001). Size scaling relationships in the active fault networks of Japan and their correlation with Gutenberg-Richter $b$ values. J Geophys Res 106(B10): 21827-21841.

Öncel A O and Wilson T (2006). Evaluation of earthquake potential along the Northern Anatolian Fault Zone in the Marmara Sea using comparisons of GPS strain and seismotectonic parameters. Tectonophysics 418(3-4): 205-218.

Peláez J A (2000). Aggregation and disaggregation of expected accelerations in the Iberian Peninsula using background seismicity. [PhD Dissertation]. University of Granada, Spain, pp. 183 (in Spanish).

Peláez J A and López Casado C (2002). Seismic hazard estimate in the Iberian Peninsula. Pageoph 159(11-12): 2699-2713.

Proyecto Sigma (1998). Analysis of the recent and current tectonic stress state from populations of faults and focal mechanisms of earthquakes. Methodology and application to the Iberian Peninsula. Collection "Other Documents", Nuclear Security Council, Madrid (in Spanish).
Sanz de Galdeano C and López Casado C (1988). Seismic sources in the Betic-Rif zone. Rev Geofis 44: 175-198 (in Spanish).

Sanz de Galdeano C, López Casado C and Peláez J A (2003). Seismic potential of the main active faults in the Granada Basin (Southern Spain). Pageoph 160(8): 1537-1556.

Sanz de Galdeano C, Shanov S, Galindo-Zaldívar J, Radulov A and Nikolov G (2010). A new tectonic discontinuity in the Betic Cordillera deduced from active tectonics and seismicity in the Tabernas Basin. J Geodyn (in press).

Scholz C H (1968). The frequency-magnitude relation of micro-fracturing in rock and its relation to earthquakes. Bull Seism Soc Amer 58(1): 399-415.

Sherman S I and Gladkov A S (1999). Fractals in studies of faulting and seismicity in the Baikal rift zone. Tectonophysics 308(1-2): 133-142.

Shivakumar K and Rao M V M S (2000). Application of fractals to the study of rock fracture and rockburst-associated seismicity. In: Dimri V P ed. Application of Fractals in Earth Sciences. A.A. Balkema, USA/Oxford, and IBH Pub. Co., New Delhi, pp. 171-188.

Singh Ch, Bhattacharya P M and Chadha R K (2008). Seismicity in the Koyna-Warna reservoir site in western India: Fractal and $b$-value mapping. Bull Seism Soc Amer 98(1): 476-482.

Singh Ch, Singh A and Chadha R K (2009). Fractal and $b$-value mapping in Eastern Himalaya and Southern Tibet. Bull Seism Soc Amer 99(6): $3529-3533$.

Smith L A (1988). Intrinsic limits on dimension calculations. Phys Lett A 113(6): 283-288.

Stanley H E, Amaral L A N, Goldberger A L, Havlin S, Ivanov P Ch and Peng C K (1999). Statistical physics and physiology: Monofractal and multi-fractal approaches. Physica A 270(1-2): 309-324.

Teotia S S (2000). Multi-fractal analysis of earthquakes: An overview. In: Dimri V P ed. Application of Fractals in Earth Sciences. A.A. Balkema, USA/Oxford, and IBH Pub. Co., New Delhi, pp. 161-170.

Udías A (1982). Seismicity and seismotectonic stress field in the Alpine Mediterranean region. In: Berckhemer $\mathrm{H}$ and $\mathrm{Hsu} \mathrm{K}$ eds. Alpine-Mediterranean Geodynamics. AGU-GSA Geodynamics Series 7, pp. 75-82.

Udías A and Buforn E (1991). Regional stresses along the Eurasia-Africa plate boundary derived from focal mechanisms of large earthquakes. Pageoph 136(4): 433-448.

Utsu $\mathrm{T}$ (1965). A method for determining the $b$-value in the formula $\log N=a-b M$ showing the magnitude-frequency relation for earthquakes. Geophys Bull Hokkaido Univ 13: 99-103 (in Japanese).

Utsu T (1966). A statistical significant test of the difference in $b$-value between two earthquake groups. J Phys Earth 14: 37-40.

Utsu T (1967). Some problems with respect to the magnitude-frequency relation of earthquakes. Geophys Bull Hokkaido Univ 17: 85-112 (in Japanese).

Vicsek T (1992). Fractal Growth Phenomena: Second Edition. World Scientific Publishing Co., pp. 495.

Xu Y and Burton P W (1999). Spatial fractal evolutions and hierarchies for microearthquakes in central Greece. Pageoph 154(1): 73-99. 